\title{
THE IMPACT OF PERSONALITY TRAITS ON THE BURNOUT PROMOTING EFFECT OF POOR SUPERVISOR SUPPORT
}

\section{FRANK HAGER}

\begin{abstract}
:
The skill of supervisors to provide adequate social support is an indispensable prerequisite for the economic success of the organization. The two-way relationship (dyad) between the leader and the led, is in the focus of this investigation. For this research in the field of social support, the moderating effects of personality traits have been considered. The question arises, as to whether they can compensate or moderate inadequate social support from supervisors and its effects on burnout. The sample comprises of managers in middle management $(\mathrm{N}=338)$ from different German automotive suppliers. In the examination, the Survey of Perceived Supervisor Support (SPSS), the German version (MBI-D) of the Maslach Burnout Inventory and the 10-Item Big-Five Inventory (BFI-10) were used. It was postulated that "neuroticism", "openness" \& "conscientiousness" have no, but "extraversion", "agreeableness" have a moderating effect between "perceived supervisor support" and the three burnout dimensions. After all, no moderating effect for all Big-5 traits was observed. Nonetheless, a negative significant correlation between the personality dimensions "openness" and the MBI dimensions "emotional exhaustion" $(r=-.245, p<.05)$ and "depersonalization" ( $r=-.301, p<.01)$ was found. Furthermore, there is a significant connection between "neuroticism" with the MBI dimension of "reduced personal accomplishment" $(r=.396$, $\mathrm{p}<.01)$.
\end{abstract}

\section{Keywords:}

perceived supervisor support, burnout, leadership, personality traits, big five

JEL Classification: M14, M54, Z13

\section{Authors:}

FRANK HAGER, University of Latvia, Latvia, Email: frank_hager@yahoo.com

\section{Citation:}

FRANK HAGER (2021). The Impact of Personality Traits on the Burnout promoting Effect of poor Supervisor Support. International Journal of Social Sciences, Vol. X(1), pp. 17-38., 10.52950/SS.2021.10.1.002 


\section{Introduction}

The actual Health Report of the BKK ${ }^{1}$ Bundesverband e. V. (2018) and also the analyses of the German Federal Ministry of Health (2018) show that the trend with regard to physical and mental health (including Burnout) continued in 2018. Since 2008, the number of days lost due to mental disorders has more than doubled $(+129.4 \%)$. This high increase is partly due to the fact that each case of illness is associated with an above-average number of days of absence (on average 37 days per case) (Pfaff \& Zeicke, 2019:27).

Based on data from DAK ${ }^{2}$ - and the "Psychoreport 2019", an estimated 2.2 million employees were affected by mental illnesses. Since 1997, the number of days of absence caused by depression or adaptation disorders has more than tripled. The most common absence is for employees diagnosed with depression. Absenteeism due to adjustment disorders has increased particularly sharply in recent years (DAK 2019).

While in the 1990s cardiovascular and respiratory complaints and musculoskeletal disorders were among the dominant groups of illnesses, this proportion of sick days is steadily declining. Otherwise, mental disorders are on the increase, especially affective, neurotic and somatoform symptoms. These developments are particularly apparent in health care workers and teaching professions, but also in public administration, management or sales - generally in occupational groups in which social contact with people is the main focus. This development becomes particularly explosive when one considers that fewer and fewer people are involved in activities in which physical work is performed. Instead, more and more people are working in more serviceoriented professions where interpersonal contact is particularly important. This results in a multitude of additional psychosocial burdens that employees from very different occupational groups have to deal with.

Certainly, the fact that employees do not have adequate coping strategies play a significant role at first glance, the problem of getting burned out seems to be exclusively on the employee's side. Nevertheless, according to the German Occupational Health and Safety Act, a supervisor is responsible for the employees who are subordinate to him. Managers have many options for action to avoid unnecessary stress ${ }^{3}$ on their teams: The creation of an appreciative and consistent management culture, clear processes and structures as well as transparent tasks are just a few examples.

The development of a health-oriented management style is much more complex. It requires the development of health-related values. And it is only these that provide orientation for the perception of the employees. This is the only way to sharpen employees' awareness of the sickening effects of excessive and insufficient demands as well as of factors that make people healthy and provide

\footnotetext{
${ }^{1}$ The BKK Dachverband e. V. (BKK DV) is a political and professional interest group as well as the central organization of Germany's company health insurance funds. The BKK umbrella association has 76 company health insurance funds with 9 million insured persons as well as four BKK regional associations.

${ }^{2}$ DAK-Gesundheit is one of the largest statutory health insurance funds in Germany and insures 5.7 million people.

${ }^{3}$ Numerous empirical studies have shown that prolonged occupational stress, which is associated with a low availability of professional and personal resources, can lead to more frequent states of exhaustion and an inner distancing from professional tasks, e. g. Demerouti et al. (2001).
} 
a higher well-being, such as job satisfaction. Health-promoting leadership behavior and the associated social support requires the professional competence and social skills of superiors. The behavior of managers has an impact on the motivation, commitment and in the following on perceived stress and burnout scores of employees - and thus ultimately on their work and employability. From a business perspective, the ability of managers to provide social support to employees is therefore an indispensable prerequisite for the economic success of the organization.

Studies confirm the link between social support by the supervisor and sickness absence as well as early retirement (Stadler \& Spieß 2004:10). In conclusion, social support from supervisors has a positive influence on the employees' perception of stress (Cohen \& Wills 1985), burnout symptoms (Leiter \& Maslach 1988), job satisfaction (Adams et al. 2018) and mental health (Kienle et al. 2006). The transition from a stress orientation to a resource-oriented perspective offers numerous starting points for health promotion. Socially supportive behavior of superiors can be described as a very important resource in the company context (Becker 2015:15).

However, the findings of supportive research are also inconsistent - characteristic are numerous studies that can confirm no or only a limited positive effect or even contradictory findings. The question arises as to what these inconsistent results can be attributed to. It is possible that other variables interact with the relationship between supervisor support and burnout? Therefore, the empirical analyses will focus on the direct and on the moderating effects of Personality traits.

For the presentation in this paper, it should be noted that although according to the WHO there is no reason to call it a disease, burnout is declared as a disease here, since there are large intersections with mental illness. Especially stress and strain are directly related to burnout. Physical and mental disorders that require the use of the health care system can still be considered as illness or disease in the sense of social science analysis, contrary to medical recommendations.

\section{Connection between Personality Traits and the Perception of social Support}

The personality of a person is understood to be the totality of all his/her permanent and psychologically relevant characteristics - such as temperamental traits, attitudes, values, motives and aspects of self-concept - which distinguish him/her from other people. The most important aspects of a person's personality are therefore the persons individual peculiarity in contrast to other people and his/her relative temporal stability. At present, personality traits of various kinds are usually located within the framework of the 5-factor model of personality. According to this model, extraversion, neuroticism, conscientiousness, agreeableness and openness - or the so-called Big Five - are the basal areas of the personality which are represented in the everyday psychological life of most people in western, but also in other cultures (Neyer 2014:235 \& 236).

With regard to the connection between perceived support and the personality of an individual there is very little evidence. In the 1980s, research was conducted which supported the finding that there is a consistent relationship with the subjective perception of social support and a wide range of health indicators. Henderson's thesis is that the correlation between perceived social support and mental health is due to a third variable. Specifically, he postulated that both mental health and the perception of social support of the social environment are determined by a person's neuroticism. Whereby neuroticism in general tends to oppose a social relationship. Neuroticism shows consistently negative associations with initiating social interactions and relationships. Neuroticism also correlates negatively with the general satisfaction with existing relationships (Lopez et al. 2003: 
654-657. Reasons could be a lack of assertiveness in social relationships, especially with regard to the assertion of personal rights and the ability to criticise other people. Röhrle further confirms the influence of various personality traits or dispositions such as self-confidence, introversion and self-esteem on the establishment and maintenance of social contacts (Röhrle 1994:160 \& 161).

In a recent study, Swickert, Hittner \& Foster found that extraversion, neuroticism and openness interacted to predict perceived social support. In other words, with a low degree of extraversion, a low degree of neuroticism was associated with greater perceived support, regardless of the degree of openness. However, with a higher degree of extraversion, the combination of low neuroticism and low openness was associated with the highest level of perceived support. At a high level of extraversion, high neuroticism and low openness were associated with the lowest level of perceived support (Swickert et al. 2010:736). Shagini, Urbanaviciute \& Rossier investigated how perceived social support affects personality, and how these variables may predict each other over time. To investigate the joint development of personality traits and perceived social support, a cross-lagged path model design was used on a sample of adults $(\mathrm{N}=1309)$ measured twice every 4 years. The results indicated that while emotional stability predicted perceived social support 4 years later, perceived social support also predicted emotional stability, extraversion, agreeableness, openness, and conscientiousness 4 years later. This suggests that perceived social support may be a resource that affects the development of personality traits known to be associated with social skills and the quality and frequency of social interactions in middle adulthood (Shagini et al. 2018:1).

Heller \& Swindle looked at the experience of support from a personal psychological perspective. They have suggested that perceptions of support have the stability of a personality characteristic (Heller \& Swindle 1983:89-92). Sarason, Sarason \& Pierce are of the same opinion. They argue similarly and describe the "sense of support" as a relatively stable quality of a person, which is formed through supportive relationships in the course of development. As the case may be that some individuals may see themselves as recipients of considerable support from others, even in the presence of evidence to he contrary. On the other hand, some people may have the tendency to see themselves as receiving minimal or no support from others (again, even in the presence of evidence to the contrary) (Sarason et al. 1990:9-25). Cobb on the other hand argues that social support is perceived differently in different situations. The perception of social support can also be reversed in certain situations (Cobb 1976:311). Cohen integrates both approaches and hypotheses that part of the explanatory variance in the support experience is probably due to characteristics of the person and part to characteristics of the situation (Cohen 1992:109-124).

There are also empirical findings speaking against the personality psychological perspective of social resources. Ludwig-Mayerhofer \& Greil tested the Henderson hypothesis and examined the inner-psychological connections between neuroticism, extraversion and frustration tolerance with the number of supporting persons as well as with the satisfaction with social support. In their model, personality traits as exogenous variables and support variables as dependent variables, perceived helpfulness and self-efficacy as endogenous variables were inserted between the personality traits as exogenous variables and the support variables as dependent variables. The perceived helpfulness, which correlated strongly with the number of supporting persons and also with the satisfaction with social support, could not be explained by personality traits neuroticism and extraversion (Ludwig-Mayerhofer \& Greil 1993:78-87). 
Members connected in social networks through relationships bring with them not only their individual life stories, but also their individual personalities. The personality contributes significantly to the shaping of the specific relationships and the entire network and, conversely, is influenced by them (Neyer 2014:233). People shape and change their social relationships in accordance with their personality. Neyer sees the reason for this in the comparatively higher stability of personality traits, which are therefore relatively immune to the influences of relationship partners or other social circumstances. In practice, this means that there are no universal rules for shaping relationships, but that they must always be considered in relation to the personality. For example, social support services in crisis situations are not equally suitable for everyone, as they are dependent on the personality and must be designed accordingly. Persons in crisis situations should therefore be advised and supported „individually”.

\section{Hypothesises}

In the first hypothesis, the aim is to test whether the frequently reported findings on the burn-out reducing or -promoting effect of social support by superiors can also be confirmed on the samples examined in this study. Burnout will be assessed by the employees themselves via the Maslach Burnout Inventory (MBI) in its three dimensions emotional exhaustion, depersonalisation and reduced personal accomplishment

Hypothesis HO - Perceived supervisor support has a significant positve effect on the three burnout-dimensions.

Additional hypotheses are developed with regard to the personality traits of the surveyed employees.

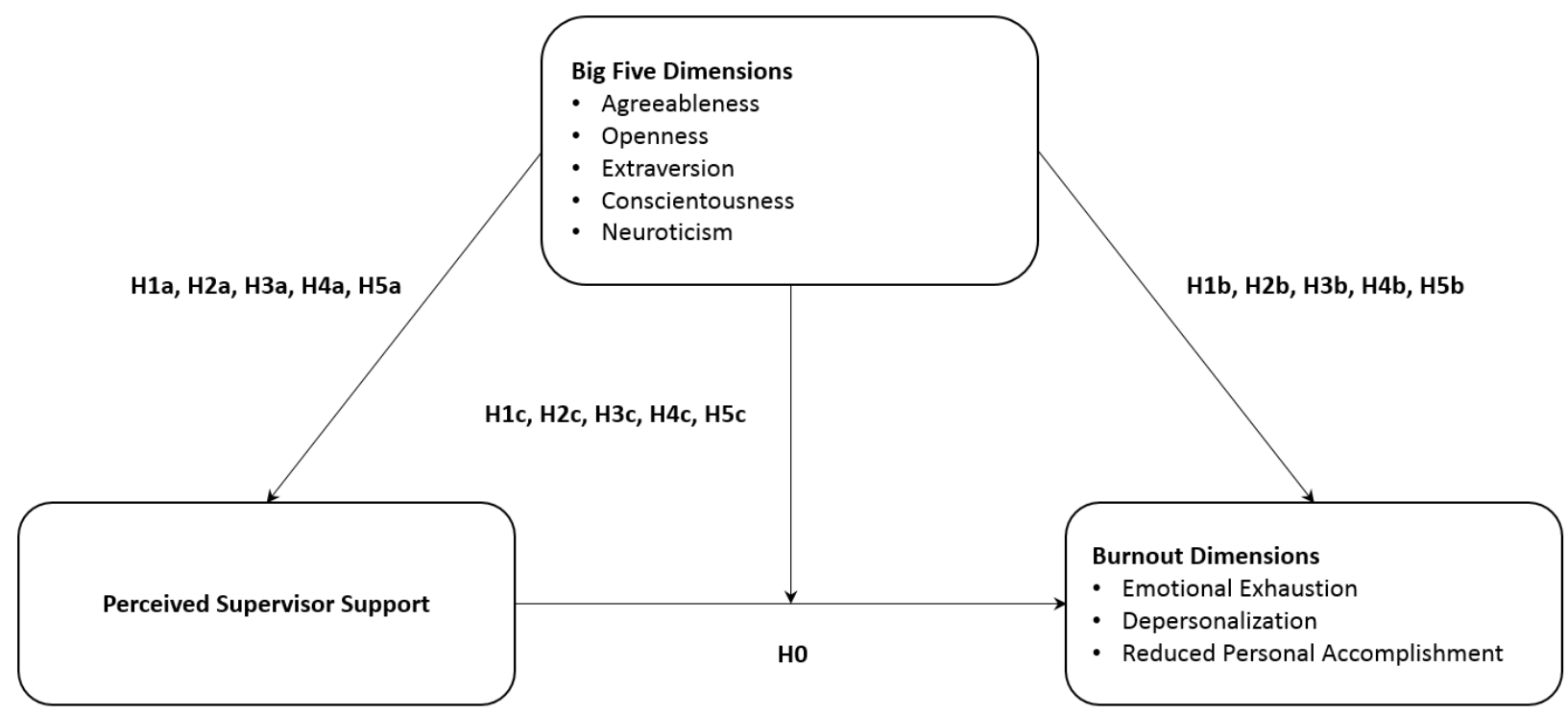

Source: author's construction.

Fig. 1: Conceptual Model and Visualization of the Hypothesises.

Neuroticism is not a mental disorder, but describes a characteristic in which all persons of a population differ more or less. Neuroticism denotes a stable, enduring personality trait and not a 
personality disorder. Neurotic people are considered to be anxious, moody, sensitive, depressed, irritable, nervous or dour. According Neyer, the quality of their social relationships is also rated rather negatively (Neyer 2014:236). In contrast, people with a low level neuroticism are emotionally stable, balanced and not so easily upset. They evaluate their social relationships positively. Of all the characteristics of the 5 -factor model ${ }^{4}$ neuroticism is considered the strongest predictor of life dissatisfaction and negative quality and instability of partnerships (Neyer 2014:236). Zellars \& Perrewé cite neuroticism as a concrete characteristic which is highly associated with perceived support and burnout dimensions (Zellars \& Perrewé 2001:459 \& 464-467). According to Judge, Heller \& Klinger, neurotic persons experience increased stress and often feel threatened by stressful situations (Judge et al. 2008:361-372).

Therefore, it is to be assumed that neuroticism is connected with the dyade employee-superior and perceived supervisor support of the employee:

Hypothesis 1a - Neuroticism has a significant negative effect on employees' perceived supervisor support.

The higher the level of neuroticism, the lower the perception of social support by the supervisor. Similarly, the hypothesis that neurotic employees have a higher risk of burnout applies in this study.

Hypothesis $1 b$ - Neuroticism has significant effects on the burnout dimensions.

The reason for this is the assumption that neurotic employees rarely use adaptive coping strategies such as positive thinking and active stress management. It cannot be assumed that neuroticism has a buffer function between perceived supervisor support and employee burnout, as it can not be seen as a resource.

Hypothesis 1c - Neuroticism has no moderating effect between perceived supervisor support and the three burnout dimensions.

People with a high degree of extraversion are open to social contacts, active, cheerful, optimistic and have comparatively many social relationships and a great potential for social support. For example, their social network is usually also more extensive than that of less extraverted people (Neyer 2014:236). When extraverts experience stress, they are more likely to establish social contact (as a coping strategy) more quickly than introverts. In addition, extraverts do not attribute failure to themselves, but rather blame their environment for certain circumstances. This in turn leads to a reduction of personal stress and emotional tension. Above all, the ability to seek out emotionally supportive sources reduces the stressful life of extraverts. In this respect, the following hypothesis can be assumed:

Hypothesis 2a - Extraversion has a significant positive effect on employees' perceived supervisor support.

Schneider, Rench, Lyons \& Riffle found unique effects on stress responses for the personality traits neuroticism (high threat and negative affect and low positive affect) but also for extraversion (high positive and low negative affect) (Schneider et al. 2012:102). Xin, Wu, Yao, Guan, Aleman \& Luo

\footnotetext{
${ }^{4}$ The Five-Factor-Model is used in the empirical part of this thesis to measure essential factors of personality. According to this model, extraversion, neuroticism, conscientiousness, agreeableness and openness - the so-called Big-Five - are the basal areas of an individual's personality.
} 
observed that individuals higher in extraversion showed smaller cortisol activation to stress and less increase of negative affect (Xin et al. 2017). There is also a lot of research on the influence of extraversion on burnout. While a high degree of neuroticism favours the occurrence of burnout symptoms, a high degree of extraversion is described as an indicator for a lower risk of burnout (Joseph et al. 2011: 276-288; McManus et al. 2011:1-18). Against this background, the following hypothesis can be made for the sample in this study:

Hypothesis $2 b$ - Extraversion has significant effects on the burnout dimensions.

At this point it can be assumed that extraversion also acts as a buffer between employees' perceived supervisor support and burnout, as this is a positive personality trait and can be drawn from resources that contribute to stress management.

Hypothesis 2c - Extraversion has a moderating effect between perceived supervisor support and the three burnout dimensions.

Among others, there are results in this regard, e. g. from Amirkhan, Risinger \& Swickert, which report that extraverts are more likely to build networks of friends than introverts. In addition, extraverts tend to use active and promblem-focused stress management strategies (Amirkhan et al. 1995:207-210).

Openness to experience refers to an area of personality characterized by active imagination, aesthetic sensitivity, attention to inner feelings, preference for diversity and intellectual wonder. Open-minded individuals are more willing than others to embrace new and unconventional ideas. They are also more creative than others, although openness is not synonymous with intelligence and educational success. By contrast, individuals with a low level of openness are more closed to themselves, tend to have conventional and conservative attitudes and are more willing to submit to authority. Openness has consequences for social relationships. Open-minded people are more sociable, which further increases their openness (Neyer 2014:236). Since the personality trait Openness assesses the extent to which a person actively seeks new experiences and reflects tolerance and a propensity to explore unknown situations, it can be concluded that individuals are equally open to and actively seek support from different sources. For this reason, the following hypothesis is made:

Hypothesis $3 a$ - Openness has a significant positive effect on employees' perceived supervisor support.

Deary, Blenkin, Agius, Endler, Zealley \& Wood discovered a modest, but significant positive relationship between the personality trait openness and the Burnout Dimension personal accomplishment (Deary et al. 1996:21-27). Zellars, Perrewè \& Hochwarter also reported a positive relationship between openness and personal accomplishment. Moreover they found a negative relationship between openness and depersonalization (Zellars et al. 1570-1598). In a longitudinal analysis of burnout in nursing students, Deary, Watson \& Hogston indicated that nurses with more open personalities were more likely to be emotionally exhausted. Therefore, in the present study, a relationship between openness and the three Burnout dimensions emotional exhaustion, personal accomplishment and deperso-nalization has been expected (Deary et al. 2003:71-81).

Hypothese $3 b$ - Openness has significant effects on the burnout dimensions. 
A moderating effect of personality trait openness on the relationship between perceived supervisor support and the three burnout dimensions is not assumed, since openness is not only seen as a strength, but can also be seen as having negative connotations and effects, as Deary, Watson \& Hogston have shown. Therefore, openness probably does not act as a classical buffer.

Hypothesis $3 c$ - Openness has no moderating effect between perceived supervisor support and the three burnout dimensions.

Agreeableness is also a feature of social behaviour and is characterised by altruism, helpfulness, understanding and compassion. Compatible people behave in a socially desirable and cooperative manner. They are rarely involved in interpersonal conflicts and are popular with their fellow human beings, while less tolerant people appear self-centered, suspicious and competitive and show a high willingness to conflict in social relationships. Compatible persons also rate the subjectively perceived closeness to their network members somewhat more in relation to genetic kinship, i. e. they are a little more oriented towards their family relationship. For this reason, the hypothesis is proposed:

Hypothesis 4a - Agreeableness has a significant effect on employee's perceived supervisor support.

Alarcon, Eschleman \& Bowling concluded from a meta-analysis that agreeableness is negatively associated with emotional exhaustion (Alarcon et al. 2009:255-259). Similar conclusions were earlier made by Zellars, Perrewè \& Hochwarter in a study using a sample of nurses. Swickert, Hittner \& Foster note, that neither agreeableness nor conscientiousness were significant predictors of perceived social support. Also Magnano, Paolillo \& Barrano found that agreeableness did not significantly predict any burnout factor (Magnano et al. 2015:15-16). Despite this ambivalent picture of outcomes, it is assumed in this paper that agreeableness might be most strongly related to the burnout dimension depersonalization. People who have an appreciative, helpful and cooperative personality will not easily fall prey to cynicism. In this respect, the hypothesis can be proposed:

Hypothesis $4 b$ - Agreeableness has a significant (negative) effect on the burnoutdimension depersonalization.

In experiencing burnout, people respond to work settings in their own unique individual way, so people may perceive specific aspects of a situation (including the given or not given social supervisor support) as more or less stressful and will react differently to situations, according to their personality characteristics personality plays a role in the stress experience, in the perception of threat and in the concomitant emotional and physiological reactions (Magnano et al. 2015:11). It can therefore be assumed that:

Hypothesis 4c - Agreeableness has a moderating effect between perceived supervisor support and the three burnout dimensions.

Conscientiousness is an aspect of self-control and manifests itself in the correct planning, organization and execution of tasks. People with high values of conscientious-ness appear determined, ambitious, diligent, persevering, reliable, punctual, orderly, but also meticulous, compulsive and controlling. In contrast, people with a low level of conscientiousness tend to be careless, indifferent and pursue their goals with little effort. In social relationships, conscientious persons feel particularly obliged to maintain and nurture certain relationships, such as in very close 
families, while less conscientious persons tend to maintain relationships of a less obligatory nature. Conscientious persons also tend to cultivate their relationships in the workplace (Alarcon et al. 2009:255-259). The results of Huang, Wang, Li \& An showed that conscientiousness has a significant positive correlation with perceived social support among firefighters (Huang et al. 2019, p. 450\&453). In a longitudinal study of middle-aged adults, Allemand, Schaffhuser \& Martin showed, that conscientiousness has significant and moderate initial level associations with all latent constructs of perceived social support (Allemand et al. 2015:17) Due to this, in this study it is assumed, that conscientiousness correlates positively and significantly with the perceived social supervisor support of employees.

\section{Hypothesis $5 a$ - Conscientiousness has a significant effect on employee's perceived supervisor support.}

Earlier research on the relationship between conscientiousness and the burnout-dimensions show rather ambivalent findings - e. g. Bakker, Van der Zee, Lewig \& Dollard in a study of volunteer counselors (Bakker et al. 2006:42) and Zellars, Perrewè \& Hochwarter in a study of nurses (Zellars et al. 1570-1598), found conscientiousness not to be significantly correlated to any of the three dimensions of burnout. Deary, Blenkin, Agius, Endler, Zealley \& Wood found conscientiousness to be negatively correlated to emotional exhaustion and reduced personal accomplishment but not to depersonalization among Scottish doctors (Deary et al. 1996:21-27).

Conscientiousness stands above all for self-control, accuracy, a sense of responsibility and determination. Many attribute this quality to a decisive influence on later professional success. People who are less conscientious are conspicuous for their carefree and spontaneous way of life. In this respect, conscientiousness could have a positive influence on the burnout dimension reduced personal accomplishment, as this is related to aspects of work engagement with its components vigor, dedication and absorbtion (Schaufeli \& Bakker 2004:295\&304-308). On the other hand, vigor and dedication are the direct positive opposites of exhaustion and cynicism, respectively. Absorption was found to be a constituting element of engagement. Therefore, it is hypothesized:

Hypothesis 5b: Conscientiousness has a significant effects on the burnout dimensions.

With regard to a possible buffer function of the two factors, no moderating effect is assumed at this point.

Hypothese $5 c$ - Conscientiousness has no moderating effect between perceived supervisor support and the three burnout dimensions.

\section{$4 \quad$ Methods}

To measure Perceived Supervisor Support, the SPSS scale has been used (Kottke \& Sharafinsky 1988:1075-1079). The SPSS scale is based on the Perceived Organizational Support Survey by Eisenberger, Huntington, Hutchinson \& Sowa - with one difference - all items refer to the supervisor, not to the organization as a global entity (Eisenberger et al. 1986:500-507). Given that the definitions of Perceived Organizational Support and Perceived Supervisor Support are practically identical in nature, their measurements have been adapted to accommodate these similarities. The SPSS consists of 16 items with a 7-point Likert scale anchored from "strongly disagree (1) to 
"strongly agree" (7). Example items include: "My supervisor really cares about my well-being." "My supervisor is willing to help me, when I need a special favour." "My supervisor tries to make my job as interesting as possible." The items "If my supervisor could hire someone to replace me at a lower salary, he/she would do so." and "If given the opportunity, my supervisor would take advantage of me." must be reversed during summation of the total values. Higher scores indicate that participants perceived their supervisors to be more supportive. Cronbach's alpha in the present study was measured at .944 .

The Maslach Burnout Inventory MBI by Maslach, Jackson \& Leiter has been used as a diagnostic tool for the detection of burnout (Maslach, Jackson \& Leiter 1996-2018). The questionnaire is regarded as the most widely used survey instrument in empirical studies of the burnout phenomenon. For this research, the German version of the Maslach Burnout Inventory (MBI-D) according to Büssing \& Perrar has been chosen (Büssing \& Perrar 1998:328-353). The MBI-D closely follows Maslach \& Jackson's item content and scaling and captures the components (according to the original MBI construct) "emotional exhaustion", "depersonalization" and "personal accomplishment". The MBI-D consists of 21 items on a six-step Likert scale with possible answers: $1=$ "nie" (never), "sehr selten" (very rare), "eher selten" (rather rare), "manchmal" (sometimes), "eher oft"(rather often) and 6= "sehr oft" (very often). Maslach, Jackson \& Leiter recommend the separate conside-ration of the three subscales. The values are calculated for each of the three scales by summation. Important to notice is, that the scale of personal accomplishment has to be calculated vice versa. In this study, the scale has been renamed in "reduced personal accomplishment" to ease the scoring and interpretation of the findings. Higher reduced personal accomplishment scores refer to lower feelings of competence and successful achievement, whereas scoring high on this subscale indicates a higher attitude of inefficacy and reduced motivation. Scoring higher on the subscale emotional exhaustion indicates greater feelings of fatigue and being drained; a higher score on the subscale depersonalisation denotes a greater tendency toward cynical, callous and uncaring attitudes against e. g. colleagues; The reliability was estimated for the subscale emotional exhaustion at .823, for the subscale depersonalization .811 and for the subscale reduced personal accomplishment .902 .

The Five-Factor-Model of personality (Big-Five-Model) is currently the most widely used model for describing the overall personality (Rammstedt et al. 2013). The model contains the five abstract dimensions (also: factors) extraversion, agreeableness, conscientious-ness, neuroroticism and openness. The BFI-10 consists of 10 items, two for each dimension of personality. Neuroticism is covered by items 4 and 9, extraversion by items 1 and 6 , openness by items 5 and 10, tolerance by items 2 and 7 and conscientiousness by items 3 and 8 . Each of the dimensions is covered by one positive and one negative item. Items $1,3,4,5$ and 7 are negatively poled. A five-level rating 
scale from "does not apply at all" (1) to "fully applies" (5) is available for the interviewee's answers (Rammstedt et al. 2013:7).

\section{$5 \quad$ Results}

In the following, the results from the correlation, regression and moderator analyses are presented. For the sake of simplicity, the presentation of the results is based on the individual tests of the hypotheses. These numbers can be taken from the corresponding concept model (Fig. 1).

\section{Testing Hypothesis HO}

The results from the correlation analysis between "perceived supervisor support" and the three burnout-dimenions "emotional exhaustion", "depersonalization" und "reduced personal accomplishment" are presented in Table 1. There was a significant correlation at the MBI dimension "emotional exhaustion" $(r=-.352, p<.01)$ and "reduced personal accomplishment" $(r=-.322, p<$ .01) found.

\section{Table 1 Pearson Correlation}

\begin{tabular}{|l|c|}
\hline \multicolumn{1}{|c|}{ MBI Burnout Dimensions } & \multicolumn{1}{c|}{ Perceived Supervisor Support } \\
\hline Emotional Exhaustion & $-.352^{\star *}$ \\
\hline Depersonalization & -.149 \\
\hline Reduced Personal Accomplishment & $-.322^{\star *}$ \\
\hline
\end{tabular}

\section{** Correlation is significant at the 0.01 level (2-tailed)}

* Correlation is significant at the 0.05 level (2-tailed)

There are no significant interactions at between all three burnout-dimensions and "perceived supervisor support" at the same time. Hence, the first hypothesis $(\mathrm{H} 0)$ is rejected. Accordingly, no significant correlation could be measured between "depersona-lization" and "perceived supervisor support". Next, a linear regression analysis was calculated for the two significant dimensions of burnout Table 1 and "perceived supervisor support" as the constant.

\section{Table 2 Regression Analysis - Model Summary}

\begin{tabular}{|l|c|c|c|c|}
\cline { 2 - 5 } \multicolumn{1}{c|}{} & $\mathrm{R}$ & R2 & Adj. & Std. \\
\hline Emotional Exhaustion & $.352 \mathrm{a}$ & .124 & .120 & 1.567 \\
\hline Reduced Personal Accomplishment & $.321 \mathrm{a}$ & .104 & .099 & 1.398 \\
\hline
\end{tabular}

a. Predictors: (Constant) Perceived Supervisor Support

The determination coefficients "emotional exhaustion" and "reduced personal accom-plishment" correspond to a medium effect (COHEN 1988). ${ }^{5} 12,4 \%$ of the variance of the "emotional exhaustion" and $10,4 \%$ of the variance of "reduced personal accomplishment" can be predicted

\footnotetext{
${ }^{5}$ According to the COHEN (1988), there is a strong effect at $R^{2} \geq .25$, a medium effect at $R^{2} \geq .09$ and a weak effect at $R^{2} \geq .01$.
} 
from "perceived supervisor support". According to ANOVA, the regression of the models makes a statistically significant prediction (Sig. .000 .050 ).

\section{Testing Hypotheses H1a, H2a, H3a, H4a, H5a}

The results from the correlation analysis between the Big-Five dimensions and Perceived Supervisor Support are presented in Table 3. A significant, medium significant correlation was observed in the Big-Five dimension neuroticism and extraversion (Table 3). Hypothesis block 2 is assessed as follows: The hypotheses $\mathrm{H} 1 \mathrm{a}$ and $\mathrm{H} 2 \mathrm{a}$ can be confirmed. "Neuroticism" in this study has a significant negative effect on "perceived supervisor support" $(r=-.363, p<.01)$. Similarly, it can be confirmed that "extraversion" has a significant positive effect on "perceived supervisor support" $(r=.389, p<.01)$. Although the Big Five - Dimension "openness" is significant $(p<.05)$, the strength of the corelation is only marginally positive $(r=.088)$. Hypothesis $\mathrm{H} 3 \mathrm{a}$ is rejected in this case. The Big-Five dimensions "agreeableness" is not significantly related to "perceived supervisor support", the hypotheses $\mathrm{H} 4 \mathrm{a}$ can therefore be confirmed. The personality trait "conscientiousness" is not significantly related to "perceived supervisor support". Hypothesis H5a is therefore rejected.

\section{Table 3 Pearson Correlation}

\begin{tabular}{|l|c|c|c|c|c|}
\cline { 2 - 6 } \multicolumn{1}{c|}{} & Neuroticism & Extraversion & Openness & $\begin{array}{c}\text { Agreeable- } \\
\text { ness }\end{array}$ & $\begin{array}{c}\text { Conscien- } \\
\text { tiousness }\end{array}$ \\
\hline Perceived Supervisor Support & $-.363^{\star *}$ & $.389^{\star *}$ & $.088^{*}$ & .233 & .114 \\
\hline
\end{tabular}

** Correlation is significant at the 0.01 level (2-tailed)

* Correlation is significant at the 0.05 level (2-tailed)

In a next step, two separate linear regression analyses were calculated for "perceived supervisor support" and the two significant Big-Five dimensions "neuroticism" and "extraversion" as constants. The dimension "openness" has been dropped due to its low correlation which is not worth to mention.

\section{Table 4 Regression Analysis - Model Summary}

\begin{tabular}{|c|c|c|}
\cline { 2 - 3 } \multicolumn{1}{c|}{} & Neuroticism & Extraversion \\
\hline $\mathrm{R}$ & $.363^{\mathrm{a}}$ & $.389^{\mathrm{a}}$ \\
\hline $\mathrm{R}^{2}$ & .132 & .151 \\
\hline Adj. $\mathrm{R}$ & .128 & .146 \\
\hline Std. Error of the Estimate & 1.865 & 2.12 \\
\hline
\end{tabular}

a. Predictors: (Constant) Perceived Supervisor Support

In the regression analysis (Table 4), according to the classification of $\mathrm{COHEN}^{6}$, a medium effect was determined for the outcome variables "perceived supervisor support". $13,2 \%$ of the variance of the "perceived supervisor support" can be predicted from "neuroticism". Simultaneously, 15,1\%

${ }^{6}$ Cohen, J. (1988). Statistical Power Analysis for the Behavioral Sciences. New York: Erlbaum. According to the author, there is a strong effect at $R^{2} \geq .25$, a medium effect at $R^{2} \geq .09$ and a weak effect at $R^{2} \geq .01$. 
of the variance of the "perceived supervisor support" can be predicted from "extraversion". According to ANOVA, the regression of the models makes a statistically significant prediction (Sig. $.000 \leq .050)$.

Testing Hypotheses H1b, H2b, H3b, H4b, H5b

The evaluation material could partially confirm the hypothesises partly. The results are presented in Table 5. The personality dimension "neuroticism" is significantly related to the burnout complaints that affected the interviewed persons $(\mathrm{H} 1 \mathrm{~b})$. This means that the more anxious and nervous the person is, the greater the limitations due to "emotional exhaustion" $(r=.421, p<.01)$. The more the person thinks about the future and is affected by self-doubt, the more his or her personal performance is limited (reduced personal accomplishment) $(r=-.396, p<.01)$.

There is also a weak correlation between "neuroticism" and "depersonalization", which means that the state of self-alienation increases accordingly with increasing neurotic personality traits $(r=.123$, $p<.05)$.

\section{Table 5 Pearson Correlation}

\begin{tabular}{|l|c|c|c|c|c|}
\cline { 2 - 6 } \multicolumn{1}{c|}{} & Neuroticism & Extraversion & Openness & Agreeableness & Conscientiousness \\
\hline Emotional Exhaustion & $.421^{* *}$ & .084 & $-.245^{*}$ & -.164 & .055 \\
\hline Depersonalization & $.123^{*}$ & .112 & $-.301^{* *}$ & -.089 & -131 \\
\hline $\begin{array}{l}\text { Reduced Personal } \\
\text { Accomplishment }\end{array}$ & $.396^{* *}$ & -.077 & .089 & .022 & -.012 \\
\hline
\end{tabular}

** Correlation is significant at the 0.01 level (2-tailed)

* Correlation is significant at the 0.05 level (2-tailed)

The hypothesis $\mathrm{H} 2 \mathrm{~b}$ could not be confirmed by the empirical calculations. This means that in this study the MBI-dimension "extraversion" had no (significant) influence on burnout symptoms of employees. There are no significant correlations.

According to expectations, a negative significant correlation between the Big-Five dimensions "openness" and the burnout dimensions "emotional exhaustion" $(r=.245, p<$ $.05)$ and "depersonalization" $(r=.301, p<.01)$ has been found. The hypothesis H3b could thus be partially confirmed. Hypotheses $\mathrm{H} 4 \mathrm{~b}$ could be confirmed. No significant correlation between the Big-Five dimensions agreeableness and the MBI-dimensions has been found in this research. Contrary to the research presented, no significant correlation with the burnout dimensions could be determined for "conscientiousness". Hypothesis H5b could thus not be confirmed.

Table 6 Regression Analysis - $\mathbf{R}^{2}$-values

\begin{tabular}{|l|c|c|}
\cline { 2 - 3 } \multicolumn{1}{c|}{} & Neuroticism (Outcome) & Openness (Outcome) \\
\hline Emotional Exhaustion & .177 & .060 \\
\hline Depersonalization & .015 & .091 \\
\hline Reduced Personal & .157 & - \\
\hline
\end{tabular}


The results of the linear regression analyses for the MBI-Dimensions and the two significant BigFive dimensions "neuroticism" and "openness" as constants are presented in Table 5. A medium effect was determined for "neuroticism" and the outcome variables "emotional exhaustion" and "reduced personal accomplishment". $17,7 \%$ of the variance of "emotional exhaustion" and 15,7\% of the variance of "reduced personal accomplishment" can be predicted from "neuroticism". Simultaneously, a medium effect $(9,1 \%)$ was determined for "openness" and the outcome variable "depersonalization". Moreover, a weak effect $(6 \%)$ was found out for "openness" and "emotional exhaustion". According to ANOVA, the regression of the models makes a statistically significant prediction (Sig. .000 $\leq .050$ ).

\section{Testing Hypotheses H1c, H2c, H3c, H4c, H5c}

The normal distribution of the dependent variable and the moderator variable which is necessary to be able to perform the analysis, is given. "Emotional exhaustion" and "reduced personal accomplishment" are set as the outcome variables, because the previous correlation analysis (Table 1) shows, that "perceived supervisor support" has a significant influence on those. This moderator analysis should check the personal traits "neuroticism" and "openness" (Table 5) for being possible moderators between "perceived supervisor support) and the MBI's significant two dimensions (Table 1). Weak predictors have been dropped.

There were no moderating effects for "neuroticism" observed. The moderator analysis could confirm hypothesis H1c. "Neuroticism" is not able to buffer (moderate) the relationship between employee's "perceived supervisor support" and the three MBI-dimensions.

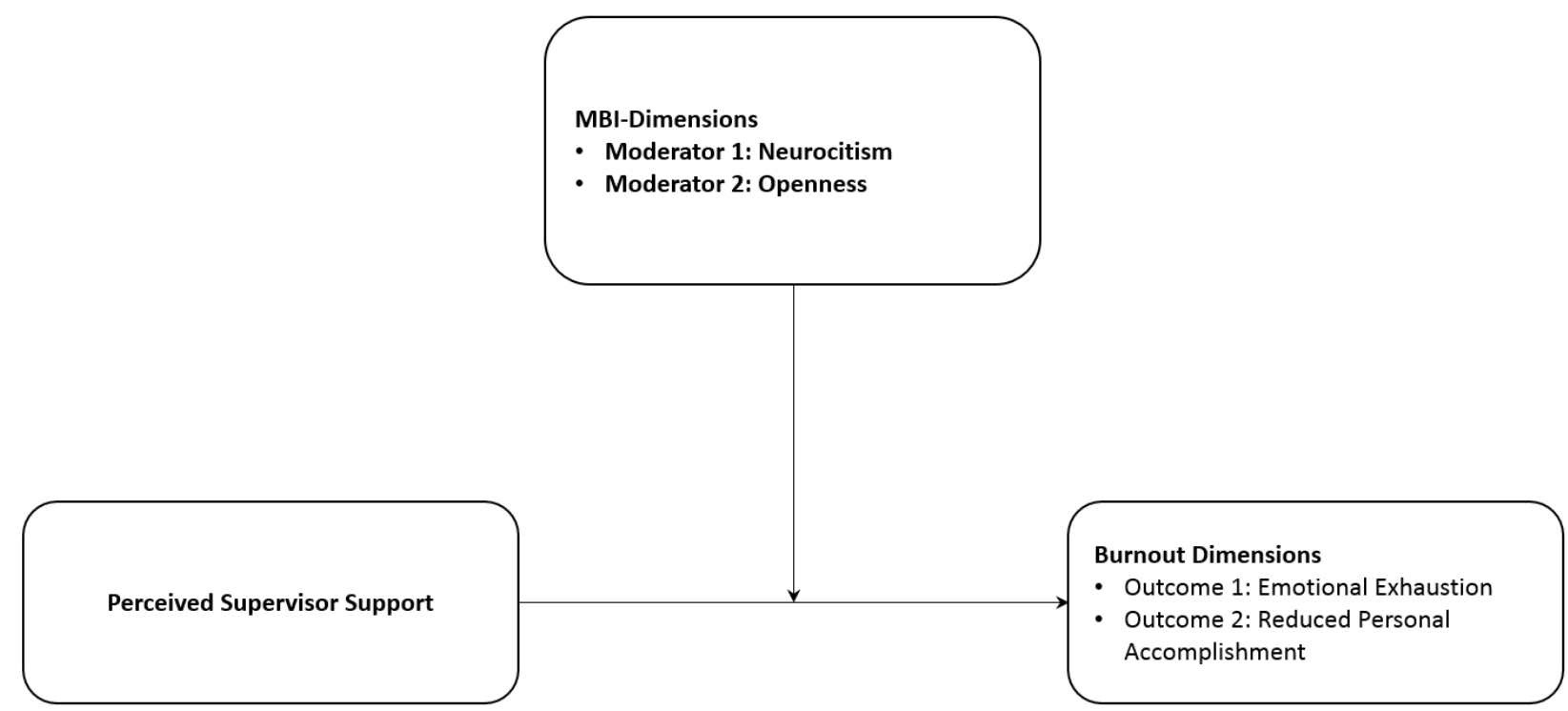

Source: author's construction.

Fig. 2: Model of the Moderator Analysis. 
As expected, "openness" has no moderating effect between "perceived supervisor support" on "emotional exhaustion). Hypothesis $\mathrm{H} 3 \mathrm{c}$ was confirmed in the moderator analysis.

Table 7 Results of the Moderator Analysis

\begin{tabular}{|l|c|c|}
\cline { 2 - 3 } \multicolumn{1}{c|}{} & Neurocitism & Openness \\
\hline $\begin{array}{l}\text { Relationship: Perceived Supervisor Support on } \\
\text { Emotional Exhaustion }\end{array}$ & $-.546 / 1.288 \mathrm{p}<, 121$ & $-2.113 / .733 \mathrm{p}<, 062$ \\
\hline $\begin{array}{l}\text { Relationship: Perceived Supervisor Support on } \\
\text { Reduced Personal Accomplishment }\end{array}$ & $-1.279 / .422 \mathrm{p}<, 101$ & - \\
\hline
\end{tabular}

The values from the regression analysis (Table 5) "extraversion", "agreeableness" and "conscientiousness" were negligible from the outset, $R^{2} \geq .01$. These were dropped due to the lack of direct effect. Hypotheses $\mathrm{H} 2 \mathrm{c}, \mathrm{H} 4 \mathrm{c}$ and $\mathrm{H} 5 \mathrm{c}$ are therefore rejected.

\section{Discussion}

The Impact of Perceived Supervisor Support on the MBI-Dimensions (HO)

In a first step, the aim of the study was to capture the „perceived supervisor support" that employees experience from their immediate supervisors and to investigate the extent to which this support predicts the development of burnout in its three dimensions. The theoretical starting point was that the positive effect of social support in connection with coping with stressful situations is transferable to dyadic supervisor-employee relationships of office-based managers - i. e. there is a connection between social supervisor support and the occurrence of burnout among the surveyed employees. A distinction of the three burnout dimensions according to Maslach; Jackson \& Leiter made it possible to obtain a more precise description of the effect of supervisor support and to explain their specific connections (Maslach, Jackson \& Leiter 1996-2018). The analyses on the prediction of burnout point to the special importance of the superior, since high levels of support are accompanied by lower levels of exhaustion.

Social supervisor support can act as a psychosocial immune system. Granted or denied, social support can directly affect the mental state of individuals - both in a positive or negative sense. In a positive way, it promotes health and helps to overcome disease. Social support is thus a prerequisite for employee-oriented and health-oriented leadership. It can take the form of tips or work relief (instrumental) as well as encouragement, comfort and motivation (emotional). Less hierarchical leadership through emotional competence counteracts burnout among employees (Vincent 2011:54). Hence, the more dissonant and dictatorial the leadership is, the more likely burnout will become noticeable among employees. Supervisor support is therefore strongly related to the emotional competence of the executive. Emotional Intelligence (EI), which became known through the psychologist and science journalist Daniel Goleman, describes the ability to perceive emotions appropriately, to use them in thought processes, and to control and understand them adequately. Goleman distinguishes between two components of Emotional Intelligence: On the one hand, social skills (in relation to oneself), which include self-perception and self-management. On the other hand social competencies (in relation to dealing with other people), which include social 
awareness and relationship management. Emotional intelligence is a prerequisite for leaders to put themselves in the shoes of employees, to perceive complex situations and to be able to react with appropriate support (Franken 2016:42).

According to Goleman, successful managers have a high emotional intelligence: „Truly effective leaders are also distinguished by a high level of emotional intelligence" (Goleman 1998:82). Emotional intelligence is based on mutual understanding and trust, empathy, sociability and contributes to synergy effects in teamwork and group learning (Franken 2016:42). Thus, if a manager can recognize negative feelings and emotions, she/he has a decisive influence on stress and finally also on the perception of exhaustion and burnout-relevant factors of the employees. In this respect, coaching sessions for managers should focus on the feelings. Managers who understand themselves and thus these inner mechanisms better have a clear psychological innovation advantage. Accordingly, also the teams, departments and companies they lead - not on the basis of a functional and therefore manipulative attitude, but on the basis of compassion, genuine empathy and sensitivity, following the principles of human dignity, respect and appreciation. Emotional intelligence should therefore not just be a catchphrase, but an important personality aspect of a successful entrepreneur and a health-oriented, supporting and burnoutpreventing leadership.

\section{The direct Effect of Personality Traits on Perceived Supervisor Support (H1a - H5a)}

This block of hypotheses dealt more comprehensively with aspects of personality in connection with the perceived support of the supervisor. For this purpose, the characteristics of the Five Factor Model were used to investigate the significance of the relevant variables. The aim was to focus on how employees and representatives of individual patterns perceive socially supportive behavior. In concrete terms, the aim was to question how perceived socially supportive behavior at work is related to individual characteristics of the person. First, correlations between the personality traits of the Five Factor Model; "extraversion", "neurocitism", "conscientiousness", "agreeableness" \& "openness" and "perceived supervisor support" were calculated. According to previous findings (e. g. Swickert, Hittner \& Forster), significant correlations between "perceived support and extraversion" ( $r=-.363 ; p<0.01)$ as well as "neuroticism" $(r=.389 ; p<0.01)$ were found in the group of surveyed employees. The coreltion with "openness" $(r=.088 ; p<0.05)$ is negligible.

For the context investigated here, this means that the perception of socially supportive behaviour by the supervisor is associated with highly extraverted behavior in individuals. Extraverted employees perceive social support by their supervisor more easily. The personality trait "neuroticism" also shows a medium but negative significant correlation. The correlations are higher for the characteristic "neuroticism" than for the personality dimension "extraversion". Accordingly, neurotic persons, i. e. emotionally unstable, vulnerable, hypersensitive, anxious and sometimes helpless employees, perceive significantly less social support from their supervisor than extraverted personalities who tend to be more dynamic, active and enthusiastic.

The result seems to be understandable, since this study focuses on the professional context, respectively the dyad of superiors and employees. While in the leisure sector there is a freedom to choose with which persons individuals surrounds themselves, this is hardly possible in this professional constellation. If the superior appears unsympathetic or selfish, gives poor support etc., 
the employee concerned will have to arrange with it. With "extraverted" personality traits, cooperation will probably be made easier and perhaps also forced, because nothing can easily upset the affected colleague and he or she can deal with the demands made on him or her and the lack of support in a relaxed manner. In order to mobilize social support, it is necessary first of all to admit to oneself, to be dependent on support and also to reveal this neediness. However, "neurocitism" makes the mobilisation more difficult (Niemann 2019:80). The "perceived social support" and the mobilisation of support services is largely determined by personal resources and personality traits. Extraverted employees have a decisive advantage in the dyad of superiors \& employee - they find it easier to establish a relationship with their superiors. In the further course of this social relationship a certain degree of empathy, the ability and willingness to cooperate as well as emotional stability is required for its maintenance and further development (Niemann 2019:80). "Neuroticism", this is how the results are interpreted, reduces trust in the social relationship and reduces the "perceived supervisor support".

\section{The direct Effect of Personality Traits on Burnout (Hypothesis H1b - H5b)}

According to expectations, a negative significant correlation between the personality dimensions "openness" and the burnout dimensions "emotional exhaution" ( $r=-.245, p<.05)$ and "depersonalisation" ( $r=-.301, p<.01)$ was found. With regard to the factor "openness" this means: the lower the "openness" values, the higher the burnout problem. The less tolerant and open an employee is, the more negatively he experiences interpersonal relationships and thus experiences long phases of constant life stress, which in turn leads to "emotional exhaustion" and "depersonalization“. This finding is surprising, since Zellars, Perrewè \& Hochwarter found only marginal significance for the dimension "depersonalisation“ (Zellars et al. 2000:1585-1590). In general, even on a meta-analytical level, weak or even no connections become apparent. Alarcon, Eschleman \& Bowling report a correlation of -.00 to „emotional exhaustion“, -.05 to „depersonalisation“ and .16 to „personal accomplishment“ (Alarcon et al. 2009:255-259). Swider \& Zimmerman come to the conclusion that there are only very few correlations $(r=-.07)$ between the components „emotional exhaustion“ and „depersonalisation“, whereas these are somewhat more pronounced with regard to „personal accomplishment“ ( $r=.16)$ (Swider \& Zimmerman:487-506). It hast to be taken into consideration, that the MBI in this study uses of a "reversed score" calculation for personal accomplishment (reduced personal accomplishment); that is asking the questions backward and then subtracting the actual score from the highest possible score.

Furthermore, there is a significant connection between "neurocitism“ with the MBI dimension of „reduced personal accomplishment" $(r=.396, p<.01)$. „Depersonalization“ can be neglected because of the weak corellation. Previous research reports have shown that the personality trait „neuroticism“ in particular causes the burnout process. Negative mood, self-doubt, dissatisfaction or imbalance and withdrawal are typical characteristics of all those persons who show high values for "neuroticism“ and below average values for „extraversion“. Thus, the results on „neuroticism“ are in line with previous researches (Bowling et al. 2004: 339-350; Bono \& Judge 2003:5-18), but in terms of "extraversion“, it is contradictory to previous findings. Contrary to expectations, it turns out that the "extraversion" dimension did not influence the burnout problem of employees in this 
study. There are no significant connections. As expected, there is also no significant connection between the Big-Five dimensions ,agreeableness"/"conscientiousness" and the MBI-dimensions.

By using these findings, managers can prevent the intensification of job burnout through being aware of their employees' personality traits. By enforcing happiness creating factors and job burnout mitigating factors, managers can control job burnout and prevent its serious consequences which hurt employees mentally and physically. With regard to the investigation of gender-specific differences in the personality dimension of „neuroticism“, earlier results could be replicated. Similar to the study by SCHMITT \& SHAKELFORD, the sample showed that women have higher levels of „neuroticism". Women were described as psychologically more unstable and more often affected by negative affects than the male test subjects. With regard to other demographic characteristics, surprisingly no significant correlations were found (Schmitt \& Shackleford 2007:246-282).

The moderating Role of Personality Traits on the Relationship between social Supervisor Support and Burnout (H1c- H5c)

As expected, no moderating effects for "neurocitism" were observed. "Neurocitism" is not able to buffer (moderate) the relationship between social support by the supervisor (perceived supervisor support) and the three MBI-dimensions. This finding could be interpreted as follows: A high level of "neuroticism" can generally be seen as a lack of resources - internal and external demands are more difficult for the person concerned to cope with. As a result, a higher stress level is created. Neurotic persons are less able to react appropriately to stress situations and activate adequate coping strategies. As a result, feelings of being overwhelmed, insecurity and possibly also a reduced perception of social support develop more quickly. It can be assumed that neurotic employees attribute the lack of (perceived) professional support by their superiors as selfdestructive. Accordingly, "neuroticism" does not have a resource function/buffer function, but, as it turned out, various direct effects on the MBI-dimensions.

As expected, "openness" has no moderating effect between "perceived supervisor support" on "emotional exhaustion". However, since comparable results are largely lacking in the literature, the task of future studies will be to examine these relationships more closely. As already noted, the values from the regression analysis (Table 5) "extraversion", "agreeable-ness" and "conscientiousness" could be neglected from the outset $R^{2} \geq .05$. These were dropped due to the lack of a direct effect.

\section{Conclusion}

Due to the direct contact with employees, supervisors at lower and middle management levels in particular are predestined to take on the task of implementing health-oriented leadership. Leiter \& Maslach see inefficient superiors as a possible cause of burnout: "Instead of holding back and giving employees the freedom to follow their ability to judge at work, supervisors want to dictate the details. They face them - but not with stimulating leadership behaviour, but with disturbing influence." (Leiter \& Maslach:70) The connection between social support and employee burnout, as well as the further influence of personality variables, presented in this paper offer initial starting points for action and concrete measures for health-oriented leadership behavior. Nevertheless, it can also be seen that health-oriented leadership is not a completely new approach. Many existing 
management concepts, such as transformational or employee-oriented management, already have a positive effect on employee health. The question is whether health- and support oriented leadership really needs to be redesigned, or whether "good and correct" leadership does not also have the positive side effect of social support for employees. The possibilities for shaping a healthy management style are therefore nothing fundamentally new for managers, but it is assumed that these are generally perceived less consciously because the influence on the operational performance process and the performance of the employees was not considered to be significant.

Accordingly, the company's goal must be to sensitize management levels to the connection between leadership and health. Only then can they initiate appropriate measures. A decisive starting point for this should be offers for managers at the level of personnel development. As an important source of impetus for the implementation of personnel development concepts, the human resources department must rethink the means by which the awareness of healthy supportive leadership can be strengthened and how existing deficits can be improved.

\section{References}

ALARCON, G.; ESCHLEMAN, K. J. \& BOWLING, N.A. (2009): Relationships between Personality Variables and Burnout: A Meta-Analysis. Work \& Stress, 23(3), pp. 244-263. https://doi.org/10.1080/02678370903282600

ALLEMAND, M.; SCHAFFHUSER, K. \& MARTIN, M. (2015): Long-term correlated Change between Personality Traits and perceived social Support in middle Adulthood. Personality and Social Psychology Bulletin, 41(3), pp. 420-432. URL: https://www.zora.uzh.ch/id/eprint/116236/1/Al lemand, $\begin{array}{llll}\text { Schaffhuser, \& Martin_PSPB_accepted.pdf. Last } & \text { retrieved: }\end{array}$ https://doi.org/10.1177/0146167215569492

AMIRKHAN, J.; RISINGER, R. \& SWICKERT, R. (1995): Extraversion: A „hidden“ Personality Factor in Coping? Journal of Personality, 63(2). Hoboken: Wiley, pp.189-212. https://doi.org/10.1111/j.14676494.1995.tb00807.x

BAKKER, A. B.; ZEE, VAN DER, K. I.; LEWIG, K. A. \& DOLLARD, M. F. (2006): The Relationship between the Big-Five Personality Factors and Burnout: A Study among Volunteer Counselors. The Journal of Social Psychology, 146(1), pp 31-50. https://doi.org/10.3200/SOCP.146.1.31-50

BECKER, P. (2015): Executive Health - Gesundheit als Führungsaufgabe. Arbeitsfreude und Unternehmenserfolg fördern. Wiesbaden: Springer. https://doi.org/10.1007/978-3-658-06072-5

BONO, J. E. \& JUDGE, T. A. (2003): Core self-evaluations: A Review of the Trait and its Role in Job Satisfaction and Job Performance. European Journal of Personality, 17, pp. 5-18. https://doi.org/10.1002/per.481

BOWLING, N. A.; BEEHR, T. A.; JOHNSON, A. L., SEMMER, N. K., HENDRICKS, E. A. \& WEBSTER, H. (2004): Explaining the Potential Antecedents of Workplace Social Support: Reciprocity or Attraction? Journal of Occupational Health Psychology, 9, pp. 339-350; https://doi.org/10.1037/1076-8998.9.4.339

BÜSSING, A., \& PERRAR, K.-M. (1992): Die Messung von Burnout. Untersuchung einer deutschen Fassung des Maslach Burnout Inventory (MBI-D). Diagnostica, 38(4), pp. 328-353.

COBB, S. (1976): Social Support as Moderator of Life-Stress. Psychosomatic Medicine, 38, pp. 300-314. https://doi.org/10.1097/00006842-197609000-00003

COHEN, J. (1988). Statistical Power Analysis for the Behavioral Sciences. New York: Erlbaum. 
COHEN, S. (1992): Stress, social Support, and Disorder. In: H. O. F. Veiel \& U. Baumann (Eds.), The Series in clinical and Community Psychology. The Meaning and Measurement of social Support. Washington: Hemisphere Publishing Corp., pp. 109-124.

COHEN, S. \& WILLS, T. A. (1985): Stress, social Support, and the Buffering Hypothesis. Psychological Bulletin, 98(2), pp. 310-357. https://doi.org/10.1037/0033-2909.98.2.310

DAK (2019): DAK Psychoreport 2019. URL: https://www.dak.de/dak/download/190725-dak-psych oreportpdf-2125500.pdf. Last accessed: 19.12.2020.

DEARY, I. J.; BLENKIN, H.; AGIUS, R. M.; ENDLER, N. S.; ZEALLEY, H. \& WOOD, R. (1996): Models of Job-related Stress and personal Achievement among Consultant Doctors. British Journal of Psychology, 87(1), pp. 3-29. https://doi.org/10.1111/j.2044-8295.1996.tb02574.x

DEARY, I, J.; WATSON, R. \& HOGSTON, R. (2003): A longitudinal Cohort Study of Burnout and Attrition in nursing Students. Journal of Advanced Nursing, 43(1), pp. 71-81. https://doi.org/10.1046/j.13652648.2003.02674.x

EISENBERGER, R., HUNTINGTON, R., HUTCHINSON, S., \& SOWA, D. (1986): Perceived organizational Support. Journal of Applied Psychology, 71, pp. 500-507. https://doi.org/10.1037/0021-9010.71.3.500

FRANKEN, S. (2016): Führen in der Arbeitswelt der Zukunft. Wiesbaden: Springer Gabler. https://doi.org/10.1007/978-3-658-11613-2

GOLEMAN, D. (1998): Working with Emotional Intelligence. New York: Bantam Books. https://doi.org/10.1002/tt. 40619981008

HELLER, K. \& SWINDLE, R. V. (1983): Social Networks, perceived social Support and Coping with Stress. In: Felner, R. D.; Jason, L. A.; Moritsugu, J. \& Farber, S. S. (Eds.), Preventive Psychology: Theory, Research and Practice in Community Intervention, New York: Pergamon Press.

HUANG, J.; WANG, X.; LI, W. \& AN, Y. (2019): The Relationship between Conscientiousness and posttraumatic Stress Disorder among young Chinese Firefighters: The mediating Effect of perceived social Support. Psychiatry Research, 273, pp. 450-455. https://doi.org/10.1016/j.psychres.2019.01.053

JOSEPH, E. N.; LUYTEN, P.; CORVELEYN, J. \& DE WITTE, H. (2011): The Relationship between Personality, Burnout, and Engagement among the Indian Clergy. International Journal for the Psychology of Religion, 21(4), pp. 276-288; https://doi.org/10.1080/10508619.2011.607412

JUDGE, T. A.; HELLER, D. \& KLINGER, R. (2008): The Dispositional Sources of Job Satisfaction: A comparative Test. Applied Psychology, 57(3), pp. 361-372. https://doi.org/10.1111/j.14640597.2007.00318.x

KOTTKE, J. L., \& SHARAFINSKY, C. E. (1988): Measuring Perceived Supervisory and Organizational Support. Educational and Psychological Measurement, 48(4), pp. 1075-1079. https://doi.org/10.1177/0013164488484024

LEITER, M. P. \& MASLACH, C. (2007): Burnout erfolgreich vermeiden. Sechs Strategien, wie Sie Ihr Verhältnis zur Arbeit verbessern. Berlin: Springer.

LOPEZ, P.; SALOVEY, P. \& STRAUS, R. (2003): Emotional Intelligence, Personality, and the perceived Quality of social Relationships. Personality and Individual Differences, 35(3). https://doi.org/10.1016/S0191-8869(02)00242-8 
LUDWIG-MAYERHOFER, W. \& GREIL, W. (1993): Soziales Netzwerk \& Soziale Unterstützung - Zum Verhältnis persönlicher und sozialer Resourcen. In: Laireiter, A. (Ed.): Soziales Netzwerk und Unterstützung: Konzepte, Methoden und Befunde. Bern: Huber, pp. 78-87.

MAGNANO, P.; PAOLILLO, A. \& BARRANO, C. (2015): Relationships between Personality and Burn-Out: An empirical Study with Helping Professions Workers. International Journal of Humanities and Social Science Research, 2015(1), pp. 10-19.

MASLACH, C.; JACKSON, S. E. \& LEITER, M. P. (1996-2018): Maslach Burnout Inventory Manual (Fourth Edition). Menlo Park: Mind Garden, Inc.

MCMANUS, I. C.; JONVIK, H.; RICHARDS, P. \& PAICE, E. (2011): Vocation and Avocation: Leisure Activities correlate with professional Engagement, but not Burnout, in a cross-sectional Survey of UK Doctors. BMC Medicine, 9(100), pp. 1-18. https://doi.org/10.1186/1741-7015-9-100

NEYER, F. J. (2014): Soziale Netzwerke und Persönlichkeit. Physikalische Medizin, Rehabilita-tionsmedizin, Kurortmedizin, 24. Stuttgart: Georg Thieme. https://doi.org/10.1055/s-0034-1390438

NIEMANN, D. (2019): Die Rolle des Partners und der Partnerin bei der Bewältigung arbeitsbe-dingter Belastungen. Der interaktive Prozess der sozialen Unterstützung in Paarbeziehungen. Wiesbaden: Springer. https://doi.org/10.1007/978-3-658-24906-9

PFAFF, H. \& ZEIKE, S. (2019): Psychische Gesundheit und Arbeit: Ein Überblick. In: Knieps, F. \& Pfaff, H. (Ed.), Psychische Gesundheit und Arbeit. BKK Gesundheitsreport 2019. Berlin: MWV Medizinisch Wissenschaftliche Verlagsgesellschaft und BKK Dachverband e. V. URL: https://www. bkkdachverband.de/fileadmin/publikationen/gesundheitsreport2019/BKK_Gesundheitsreport_20 19_eBook.pdf. Last accessed: 20.10.2020.

RAMMSTEDT, B.; CHRISTOPH, J.; KEMPER, M.; KLEIN, C.; BEIERLEIN, C. \& KOVALEVA, A. (2013): Eine kurze Skala zur Messung der fünf Dimensionen der Persönlichkeit: Big-Five-Inventory-10 (BFI-10), Working Papers, 2012/23. Mannheim: GESIS - Leibniz-Institut für Sozialwissen-schaften.

RÖHRLE, B. (1994): Soziale Netzwerke und soziale Unterstützung. Weinheim: PVU.

SARASON, B. R.; SARASON, I. G. \& PIERCE, G. R. (1990): Traditional Views of social Support and their Impact on Assessment. In: Sarason, B. R., Sarason, I. G. \& Pierce, G. R (Eds.), Social Support: An interactional View.

SCHAUFELI, W. B. \& BAKKER, A. B. (2004): Job Demands, Job Resources, and their Relationship with Burnout and Engagement: A Multi-Sample Study. Journal of Organizational Behavior, 25. New York, pp. 293-315. https://doi.org/10.1002/job.248

SCHMITT, D. P. \& SHACKLEFORD, T. K. (2008): Big Five Traits related to short-term Mating: From Personality to Promiscuity across 46 Nations. Evolutionary Psychology, 6(2), pp. 246-282. https://doi.org/10.1177/147470490800600204

SCHNEIDER, T. R.; RENCH, T. A.; LYONS, J. B. \& RIFFLE, R. R. (2012): The Influence of Neuroticism, Extraversion and Openness on Stress Responses. Stress and Health: Journal of the International Society for the Investigation of Stress, 28, pp. 102-110. https://doi.org/10.1002/smi.1409

SHAGINI, U.; URBANAVICIUTE, I. \& ROSSIER, J. (2018): Perceived social Support and Big-Five Personality Traits in middle Adulthood: A 4-Year Cross-Lagged Path Analysis. Applied Research in Quality of Life, Amsterdam: Springer Nature, p. 1.

STADLER, P. \& SPIEß, E. (2004): Mitarbeiterorientiertes Führen und soziale Unterstützung am Arbeitsplatz. Grundzüge und Beispiele eines Informations- und Handlungskonzepts. Dortmund: Bundesanstalt für Arbeitsschutz und Arbeitsmedizin. 
SWICKERT, R. J.; HITTNER, B. H. \& FOSTER, A. (2010): Big Five Traits interact to predict perceived social Support. Personality and individual Differences. Amsterdam: Elsevier, 48(6). https://doi.org/10.1016/j.paid.2010.01.018

SWIDER, B. W. \& ZIMMERMAN, R. D. (2010): Born to burnout: A meta-analytic Path Model of Personality, Job Burnout, and Work Outcomes. Journal of Vocational Behavior, 76(3). Amsterdam: Elsevier, pp. 487-506. https://doi.org/10.1016/j.jvb.2010.01.003

VINCENT, S. (2011): Gesundheits- und entwicklungsförderliches Führungsverhalten: Ein Analyseinstrument. In: Badura, B.; Ducki, A.; Schröder, H.; Klose, J.; Macco, K. (Eds.): Fehlzeiten-Report 2011, Führung und Gesundheit, Zahlen, Daten, Analysen aus allen Branchen der Wirtschaft. Berlin, Heidelberg: Springer. https://doi.org/10.1007/978-3-642-21655-8_5

XIN, Y., WU, J.; YAO, Z.; GUAN, Q., ALEMAN, A. \& LUO, Y. (2017): The Relationship between Personality and the Response to acute psychological Stress. Scientific Reports, 7(1) [16906]. https://doi.org/10.1038/s41598-017-17053-2

ZELLARS, K. L. \& PERREWÉ, P. L. (2001): Affective Personality and the Content of emotional social Support: Coping in Organizations. Journal of Applied Psychology, 86(3), pp. 459 \& 464-467. https://doi.org/10.1037/0021-9010.86.3.459

ZELLARS, K. L., PERREWĖ, P. L. \& HOCHWARTER, W. A. (2000): Burnout in Health Care: The Role of the Five-Factors of Personality. Journal of Applied Social Psychology, 30(8), pp. 1570-1598. https://doi.org/10.1111/j.1559-1816.2000.tb02456.x 